\title{
Steroid Sensitive Nephrotic Syndrome in children: What steroid regime for the initial attack?
}

\author{
Jayantha UK \\ Department of Paediatrics, Faculty of Medicine, University of Ruhuna, Sri Lanka \\ (Extracts of the GMAOration 2011)
}

Correspondence: Prof.U.K.Jayanatha (u_k_jayantha@yahoo.com)

Nephrotic syndrome is a condition in which the glomeruli of the kidney leak protein from blood into the urine. It results in hypoproteinaemia and oedema. Incidence of childhood nephrotic syndrome in Europe and North America is 2 per 100,000 children, whereas in Asian countries the incidence is 16 per 100,000 (1). The majority of children have minimal change disease and the cause is unknown in $90 \%$ of them (2).

Corticosteroids have been used to treat children with nephrotic syndrome since 1950 and have shown significant reduction in mortality and morbidity. Of the children who present with their first episode of nephrotic syndrome, approximately $95 \%$ will achieve remission with corticosteroid therapy (1).

Corticosteroid usage has reduced the mortality rate in childhood nephrotic syndrome to around 3\%, while infections remain the most important cause of death (3). About $70 \%$ of children who respond to corticosteroids experience a relapsing course with recurrent episodes of oedema and proteinuria. Children with untreated nephrotic syndrome are at increased risk of bacterial infections, characteristically resulting in peritonitis, cellulitis or septicemia, thromboembolic phenomenon and protein calorie malnutrition. Before the antibiotics become available, nearly two thirds of children with nephrotic syndrome died with overwhelming infections (4). However corticosteroids have known adverse effects such as obesity, poor growth, hypertension, diabetes mellitus, osteoporosis and adrenal suppression which are to be kept in mind when designing a steroid regime for nephrotic syndrome. Adverse effects due to steroids are particularly prevalent in those children who relapse frequently and thus require repeated courses of corticosteroids.
The original treatment schedule for childhood nephrotic syndrome has been developed in an ad-hoc manner. The International Study of Kidney Disease in Children (ISKDC) was established in 1966 and determined by consensus, a regimen of daily corticosteroids for four weeks followed by three consecutive days of a week for four weeks or alternate day for four weeks (4).

Children relapsing early in their illness continue to have a stronger tendency to relapse throughout their illness than those without early relapses (5). Non relapsing course for two consecutive years predicts an excellent prognosis. Number of relapses that occur during the first six months is highly predictive of the subsequent course (6). Although it is well accepted that corticosteroid induces a complete remission in most children with idiopathic nephrotic syndrome, the optimal duration of initial steroid treatment is unclear (7).

However the optimal dose and duration of corticosteroid therapy that is most beneficial and least harmful remains to be clarified. In determining the above, following objectives have to be full-filled such as to achieve a prolonged duration of remission, to maintain growth velocity at normal or near normal level, to avoid relapses during the initial 6 months of follow up and to reduce the number of relapses per patient per year.

Since there is no consensus on the steroid regime to be used in the initial attack of steroid sensitive nephrotic syndrome a survey was done in the United States and Canada a few years ago. Thirty nine percent of Nephrologists believed that a longer steroid regime results in more sustained remission, but $42 \%$ were not convinced and $19 \%$ did not believe that prolonged course of steroid has any benefit (8). 
I involved in determining the optimal dose and duration of steroid therapy for the initial attack of nephrotic syndrome since 1994 by collecting data from a long standing randomised controlled trial. According to the reviewers of the Cochrane renal library, this study seems to be the largest and the longest study on corticosteroid therapy in childhood nephrotic syndrome.

We have followed up two groups of randomly selected steroid sensitive nephrotic syndrome children, receiving steroid regime similar to ISKDC regime and an experimental regime (7 months steroid regime) Seven month steroid regimen consisted of prednisolone $60 \mathrm{mg} / \mathrm{m}^{2}$ daily for 28 days, then alternative day for another 28 days and taper by $10 \mathrm{mg} / \mathrm{m}^{2} / \mathrm{month}$, up to seven months.

Reviewers of the Cochrane renal library have accepted this study as an ongoing study to publish in the Cochrane database since 2002 among the other internationally recognized studies such as International Study in Kidney Diseases in childhood.

Prolonged steroid therapy lengthens the duration of remission in patients with initial attack of nephrotic syndrome when compared to two months regime (9). Seven months steroid therapy in steroid sensitive nephrotic syndrome with an initial attack would results in significantly lesser number of relapses.

In a randomized controlled trial only 16 out of 35 patients relapsed after 24 months of follow up with seven months steroid regime when compared to 43 out of 53 with two months regime ( RR $0.56,95 \%$ CI 0.38 to 0.83$)(10)$.

Steroid side effects are dependant on the total dose of steroid used in a particular patient. Since patients treated with prolonged steroid regimes were experiencing a lesser number of relapses, the cumulative dose of steroid received by an individual patient was significantly lower when compared to short course of steroid therapy (11).

In my presentation I would like to produce the data of the final analysis of my 15 yrs of study which was not published before and the details of the systematic analysis of data in the Cochrane database on the steroid therapy in nephrotic syndrome. Some of the alternative -therapy adopted by me in the management of steroid sensitive nephrotic syndrome also will be discussed.
This study was started in 1994. Children with steroid sensitive nephrotic syndrome were randomly allocated to either ISKDC regime of steroids (60 $\mathrm{mg} / \mathrm{m}^{2} /$ daily for 28 days, followed by $40 \mathrm{mg} / \mathrm{m}^{2} / \mathrm{EOD}$ for 28 days) or to 7 months steroid regime (prednisolone $60 \mathrm{mg} / \mathrm{m}^{2} /$ daily for 28 days followed by $60 \mathrm{mg} / \mathrm{m}^{2} / \mathrm{EOD}$ for 28 days. Then the dose of steroid was reduced by $10 \mathrm{mg} / \mathrm{m}^{2} /$ monthly until 10 $\mathrm{mg} / \mathrm{m}^{2} / \mathrm{EOD}$ ). Patients presenting with the initial attack of nephrotic syndrome were included, in the study.

There were 86 patients in the ISKDC regime (mean age of onset 48.95 months, SD 29.45) and 79 in the 7 months regime (mean age of onset 48.25 months, SD 29.50). The mean duration remissions in ISKDC regime was 5.1 months (SD 3.21) whereas in the7 months regime it was 25 months (SD 18.55).

At the end of 2 yrs of follow up cumulative mean relapse rate in ISKDC group was 4.18 (SD 2.81) and in the 7 months group was 0.99 (SD 1.13). This difference was statistically significant. Corresponding figures at $5 \mathrm{yrs}$ of follow up was 9.26 (SD 5.88) and 1.52 (SD 1.58), respectively. Hence the results show a significantly lower cumulative mean relapse rate with the experimental 7 months regime.

Results also show that in long term follow up the cumulative steroid dose received by the 7 months regime was lower than the ISKDC group. After completion of 5 yrs of follow up mean cumulative steroid received by ISKDC group was $10.1 \mathrm{~g}$ (SD 4.97) while in the 7 months group it was $9.2 \mathrm{~g}$ (SD 4.01). This finding also explained by the lower relapse rate in 7 months regime although it gives a higher total dose at a time.

A randomized controlled trial was carried out to determine the necessity of the use of daily prednisolone for 28 days in the initial episode of nephrotic syndrome by giving a short daily course of prednisolone to the control group. Results showed that if the duration of daily prednisolone therapy is reduced, there would not be any benefit even through the total duration of therapy extended up to 7 months (12).

Frequent relapsing nephrotic syndrome and the steroid dependency are the long standing problems in patients with nephrotic syndrome. In this long term follow up study the patients who have been treated with prolonged steroid course have shown 
lesser number of patients with frequent relapsing or steroid dependent status.

But still the steroid dependency and the frequent relapsing state are the main problems in long term follow up. According to the results of the original study at $5 \mathrm{yr}$ of follow up, $64 \%$ of patients with ISKDC regime and only $14 \%$ of patients with 7 months steroid regime have developed frequent relapsing / steroid dependent state (13).

Cyclophosphamide is a better alternative for steroid in frequent relapsing nephrotic syndrome. By the use of cyclophosphamide, mean relapse rate of patients with frequently relapsing nephrotic syndrome have reduced from 4.5 / year to 1.1 / year (14).

Steroid dependency is still a difficult group to manage. Cyclophosphamide, cyclosporine and levamisole do not give satisfactory results especially when high dose steroid dependency exists. Captopril is shown to reduce the relapse rate as well as the maintenance dose of steroids required in those patients with steroid dependent nephrotic syndrome (16).

In a study of 36 children with steroid dependent nephrotic syndrome mean relapse rate was reduced with captopril therapy from 4 / per yr to 1.3 per year and the mean prednisolone dose required was reduced from $1.48 \mathrm{mg} / \mathrm{kg}$ to $0.45 \mathrm{mg} / \mathrm{kg}$ (17). It also reduced the cumulative dose of steroid used, obviously because of the lesser number of relapses and the use of very small dose of steroids (17).

According to the Cochrane database, prolonged steroid course in the initial attack of nephrotic syndrome results in favourable outcome when compared with a control group with 2 months steroid therapy. Summary of the meta-analysis is given below relevant to the relapse rate at 6 months and 24 months of follow up (Tables 1 and 2).

Table 1: Steroid therapy in first episode of nephrotic syndrome: Comparisons with ISKDC standard therapy. Number of Children relapsing by 6 months. (The Cochrane library 2008 issue 1)

\begin{tabular}{|c|c|c|c|c|}
\hline Study & $\begin{array}{l}\text { Experiment } \\
\mathbf{n} / \mathbf{N}\end{array}$ & $\begin{array}{l}\text { t Control } \\
\mathbf{n} / \mathbf{N}\end{array}$ & $\begin{array}{l}\text { I Relative risk } \\
\text { (Random) } \\
95 \% / C I\end{array}$ & Prednisolone dose in the experimental group \\
\hline $\begin{array}{l}\text { APN } \\
1993\end{array}$ & $8 / 34$ & $18 / 37$ & $0.48(0.24,0.96)$ & $\begin{array}{l}\mathrm{P} 60 \mathrm{mg} / \mathrm{m}^{2} / \mathrm{d} \text { for } 4 \text { weeks and } \\
40 \mathrm{mg} / \mathrm{m}^{2} / \mathrm{EOD} \text { for } 6 \text { weeks } \\
\text { (3 months) }\end{array}$ \\
\hline $\begin{array}{l}\text { Bagga } \\
1999\end{array}$ & $13 / 22$ & $18 / 23$ & $0.76(0.50,1.14)$ & $\begin{array}{l}\mathrm{P} 60 \mathrm{mg} / \mathrm{m}^{2} / \mathrm{d} \text { for } 64 \text { weeks } \\
40 \mathrm{mg} / \mathrm{m}^{2} / \mathrm{EOD} \text { for } 6 \text { weeks then } \mathrm{P} 40 \mathrm{mg} / \mathrm{m}^{2} / \mathrm{d} \\
\text { for } 4 \mathrm{weeks} \\
30 \mathrm{mg} / \mathrm{m}^{2} / \mathrm{EOD} \text { for } 4 \text { weeks ( } 4 \text { months) }\end{array}$ \\
\hline $\begin{array}{l}\text { Jayantha } \\
2002\end{array}$ & $5 / 48$ & $48 / 74$ & $0.16(0.07,0.37)$ & $\begin{array}{l}\mathrm{P} 60 \mathrm{mg} / \mathrm{m}^{2} / \mathrm{d} \text { for } 4 \text { weeks alternative day for } \\
4 \text { weeks and taper by } \\
10 \mathrm{mg} / \mathrm{m}^{2} / \text { month) } 7 \text { months }\end{array}$ \\
\hline $\begin{array}{l}\text { Ksiazek } \\
1995\end{array}$ & $25 / 72$ & $28 / 44$ & $0.55(0.37,0.80)$ & $\begin{array}{l}\mathrm{P} 60 \mathrm{mg} / \mathrm{m}^{2} / \mathrm{d} \text { for } 4 \text { weeks } \\
30 \mathrm{mg} / \mathrm{m}^{2} / \text { EOD for } 4 \text { weeks, reduced by } 25 \% \\
\text { each month ( } 5 \text { months })\end{array}$ \\
\hline $\begin{array}{l}\text { Ueda } \\
1998\end{array}$ & $4 / 17$ & $17 / 29$ & $0.40(0.16,1.00)$ & $\begin{array}{l}\mathrm{P} 60 \mathrm{mg} / \mathrm{m}^{2} / \mathrm{d} \text { for } 4 \text { weeks alternate days for } \\
4 \text { weeks and taper by } 10 \mathrm{mg} / \mathrm{m}^{2} / \mathrm{month} \\
(7 \text { months) }\end{array}$ \\
\hline
\end{tabular}


Table 2: Steroid therapy in first episode of nephrotic syndrome: Comparisons with ISKDC standard therapy: Number of Children relapsing by 24 months.

(The Cochrane library 2008 issue 1)

\begin{tabular}{llll}
\hline Study & \multicolumn{1}{c}{$\begin{array}{c}\text { Experiment } \\
\mathbf{n} / \mathbf{N}\end{array}$} & $\begin{array}{c}\text { Control } \\
\mathbf{n} / \mathbf{N}\end{array}$ & $\begin{array}{c}\text { Relative risk (Random) } \\
\mathbf{9 5 \%} / \mathbf{C I}\end{array}$ \\
\hline APN 1993 & $13 / 34$ & $24 / 37$ & $0.59(0.36,0.96)$ \\
Bagga 1999 & $16 / 22$ & $21 / 23$ & $0.80(0.60,1.06)$ \\
Jayantha 2002 & $16 / 35$ & $43 / 53$ & $0.56(0.38,0.83)$ \\
KsiaZek 1995 & $36 / 72$ & $32 / 44$ & $0.69(0.51,0.92)$ \\
Ueda 1998 & $5 / 17$ & $18 / 29$ & $0.47(0.22,1.04)$ \\
\hline
\end{tabular}

\section{Conclusions}

1. Nephrotic syndrome is a common paediatric problem but still there is no consensus on the duration of steroid therapy. As a result, there are many steroid regimes available worldwide.

2. Prolonged course of steroid on the first episode has produced (steroid therapy for 7 months) significantly favorable results when compared to the conventional therapy (ISKDC regime - 2 months therapy) with regards to duration of remission

- Percentage of relapses

- Relapse rate / patient/ year

- Cumulative dose of steroid received

3. There is no significantly higher incidence of adverse effects with prolonged therapy.

4. Frequent relapsing nephrotic syndrome and steroid dependency are significantly low with prolonged steroid therapy.

5. Prednisolone therapy for 1 month in the initial phase is very essential to achieve good results. Just lengthening the course of steroid will not be beneficial unless the daily prednisolone therapy is continued for one month.

6. Frequent relapsing nephrotic syndrome could be better managed with cyclophosphamide given orally or with intravenous monthly pulse therapy.

7. Captopril is a safe and effective drug that could be used in steroid dependent nephrotic syndrome.
8. Considering all above facts we recommend that the initial attack of nephrotic syndrome should be given prednisolone daily for one month followed by gradual tapering to alternative day therapy for another 6 months to achieve maximum benefits. For patients who develop frequent relapsing state, it is better to consider cyclophosphamide and in steroid dependent state to consider captopril before the other expensive and toxic drugs.

\section{References}

1. Hodson EM, Knight TF, Willis NS, Craig JC. Steroid therapy in nephrotic syndrome. Archives Diseases in Childhood, 2000; 83: 54-57.

2. Sharples PM, Poulton J, White RH. Steroid responsive nephrotic syndrome in Asians. Arch. Dis Child, 1985; 60: 1014-17.

3. Effects of cytotoxic drugs in frequently relapsing nephrotic syndrome. New England Journal of Medicine, 1982; 306(8): 451-4.

4. Arncil GC. International trial of azathioprine in nephrotic syndrome in childhood. Nephrone, 1971;8: 95.

5. Atsushi Takeda treatment of nephrotic syndrome. Pediatr Nephrol, 2001;16: 888-93.

6. International study of Kidney disease in children Corticosteroid therapy in childhood Nephrotic Syndrome. $J$ Pediatr, 1982; 101: 514-518.

7. Mare B Lance. Steroid therapy in nephrotic syndrome. Pediatr Nephrol, 2003; 18: 342-46. 
8. Niaudet P, Broyer M. Management of steroid sensitive nephrotic syndrome. Pediatr Nephrol, 200; 14: 770-771.

9. Jayantha UK. Comparison of ISKDC regime with a 7 month steroid regime in steroid sensitive nephrotic syndrome. $7^{\text {th }}$ Asian Congress of Paediatric Nephrology, Singapore Nov 2000.

10. Jayantha UK. Comparison of ISKDC regime with a 7 months steroid regime in the initial article $13^{\text {th }}$ Congress of International Paediatric Nephrology Association, Congress of International Paediatric Nephrology Association, Adelaide Sept 2005.

11. Jayantha UK. Comparison of ISKDC regime within 7 months steroid regime in the first attack of nephrotic syndrome (abstract). Pediatric Nephrology, 2004; 19: c81.

12. Jayantha UK. Does daily prednisolone for 1 month is beneficial in the first attack of nephrotic syndrome: Paediatric Nephrology, 2004; 19: c98.
13. Jayantha UK. Wijayasiri WAA. Study of pattern of relapse in patients with nephrotic syndrome in two different regime of steroid therapy. Annual Academic Sessions, Galle Medical Association, Sept.2004.

14. Jayantha UK. Beneficial effects of cyclophosphamide in patients with frequent relapsing nephrotic syndrome. Sri Lanka Journal of Child Health, 2007: 36: 133-4.

15. Captopril: A new approach to steroid dependent nephrotic syndrome. $7^{\text {th }}$ Asian Congress of Paediatric Nephrology, Singapore Nov. 2000.

16. Captopril therapy in children with steroid dependent nephrotic syndrome. Sri Lanka Medical Association, Annual Academic Sessions 2003.

17. Jayantha UK. Long term follow up of steroid dependent Nephrotic syndrome patients with captopril therapy. Paediatric Nephrology, 2004: 19. 